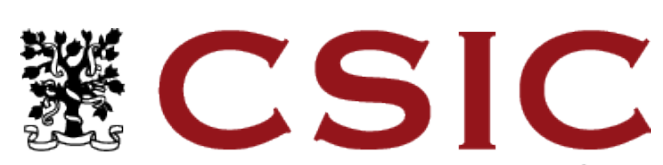

\section{The seismic structure of the West Iberian continent-ocean transition}

\section{Irene Merino}

César R. Ranero - Valenti Sallarès - Manel Prada 


\section{Survey - OBS/OBH data}

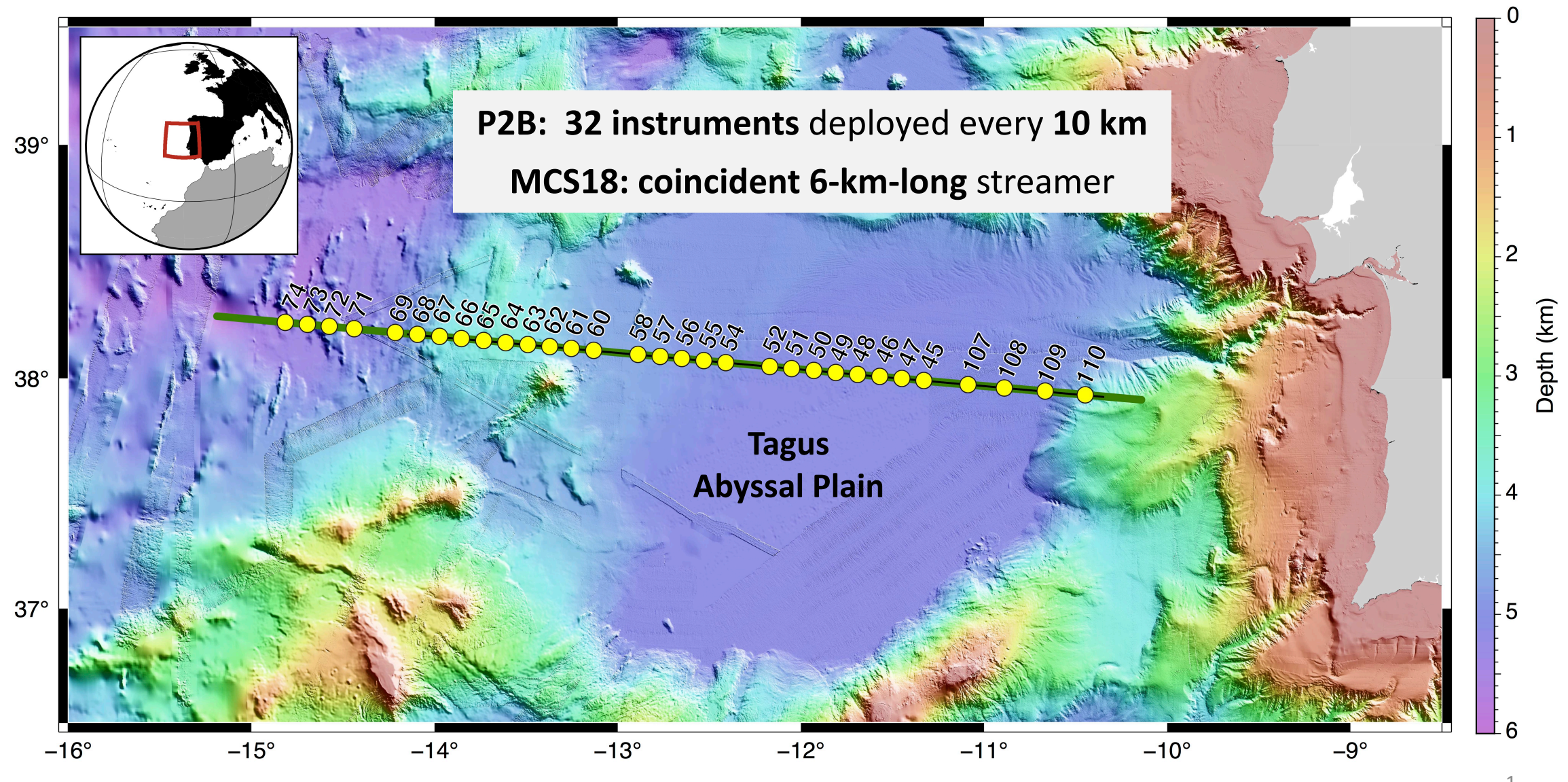




\section{Picking Wide-Angle Seismic data}

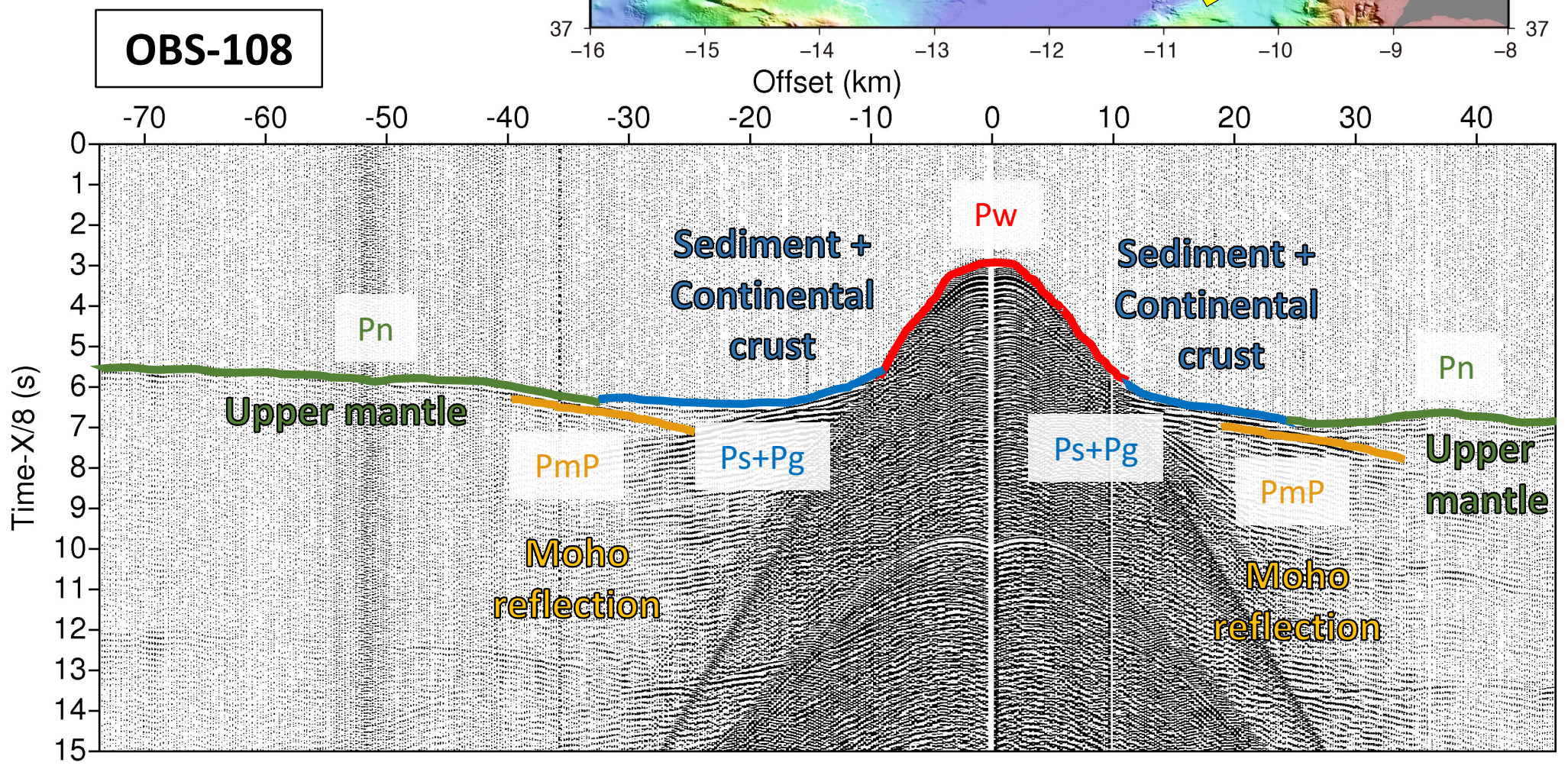




\section{Picking Wide-Angle Seismic data}

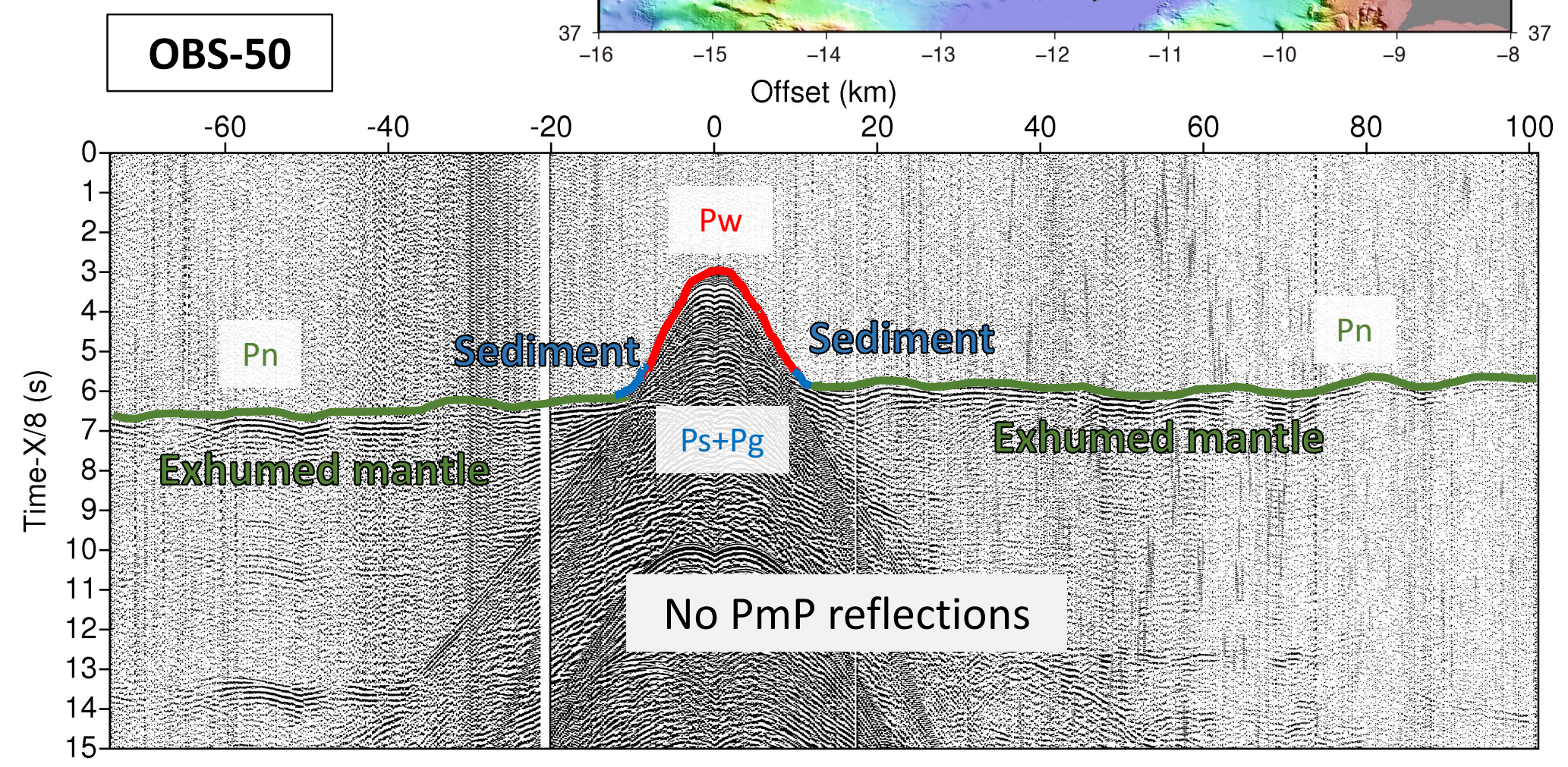




\section{Picking Wide-Angle Seismic data}

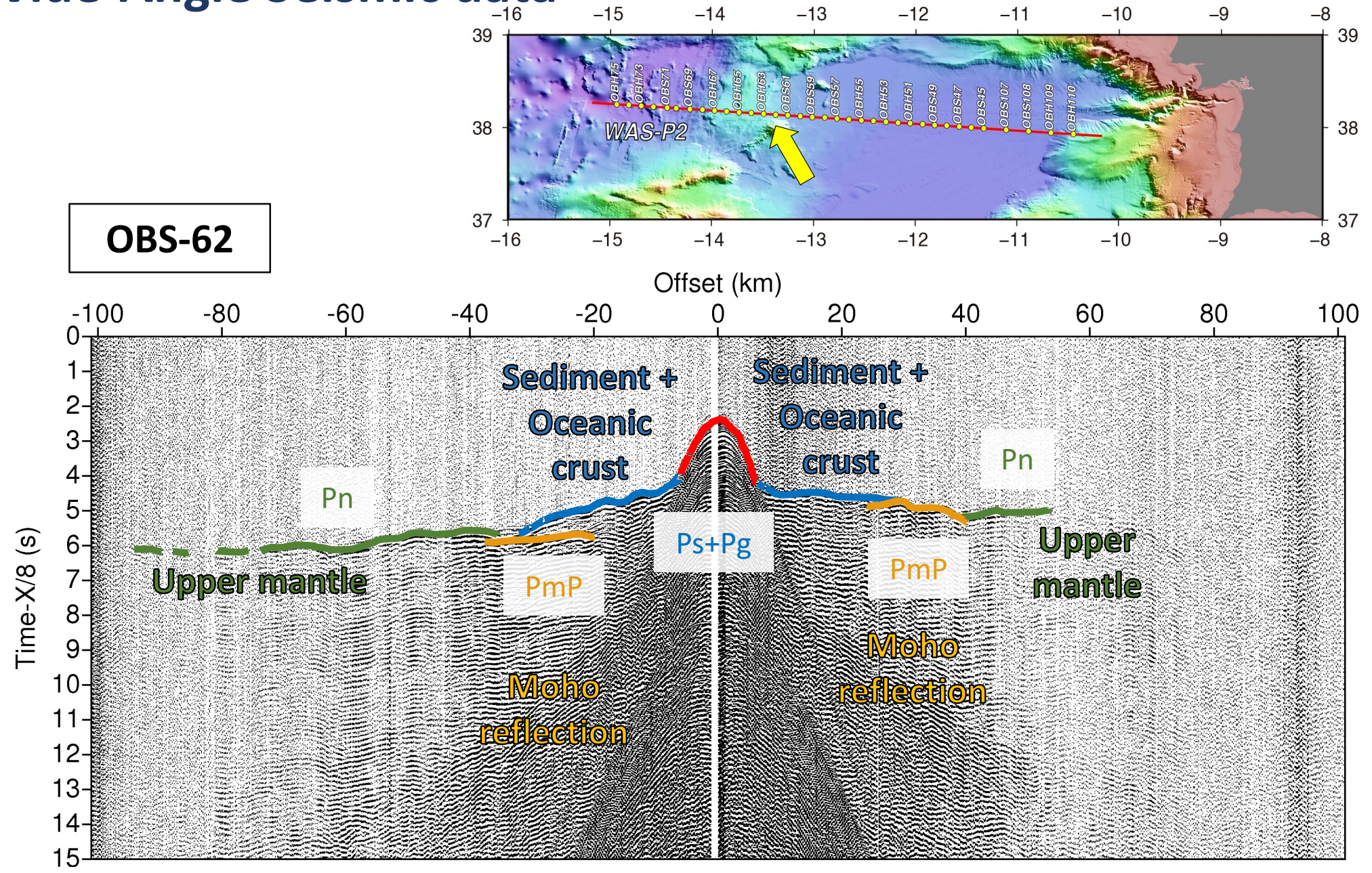




\section{Interpretation from the P-waves velocity model}

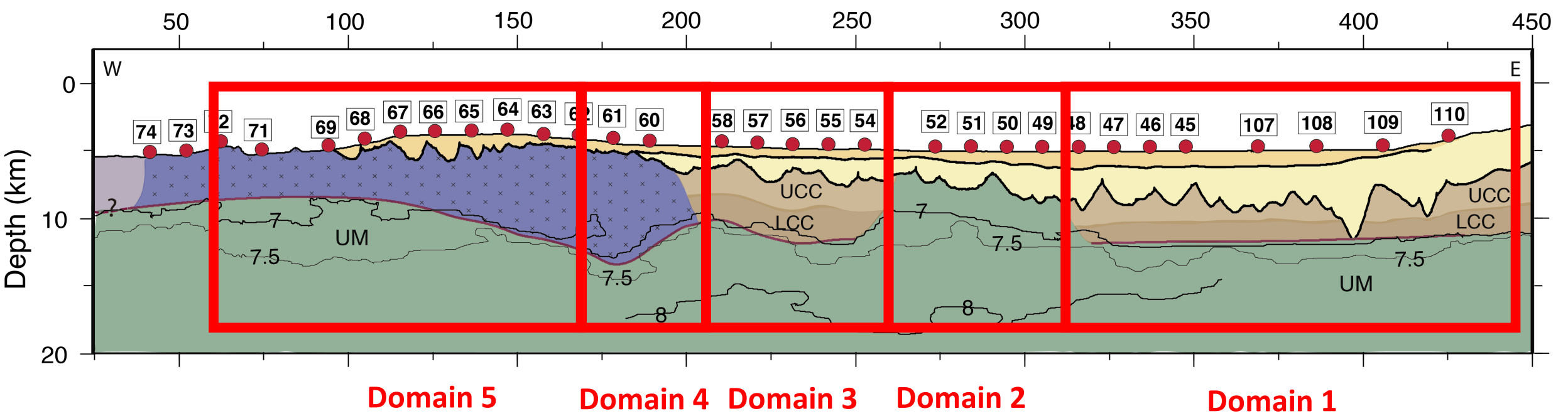

- To define the nature of the rock of the basement we need accurate velocity models that determine the distribution of the velocity with depth.

- Our velocity model is divided in 5 domains, showing a different structure from the previous models:

- An exhumed mantle domain (75 km wide)

- 2 continental domains : one extending from the margin and a 50-km-wide ribbon west of the exhumed mantle

- A oceanic domain showing that the first pulse was thicker than the later steady state seafloor spreading to the west. 